Original

\title{
Effect of gutta-percha solvents on fiberglass post bond strength to root canal dentin
}

\author{
Orlando A. Guedes ${ }^{1)}$, Gustavo S. Chaves'), Ana H. G. Alencar'), Álvaro H. Borges'), \\ Cyntia R. A. Estrela1), Carlos J. Soares ${ }^{3)}$, and Carlos Estrela ${ }^{2)}$ \\ 1)Endodontic Division, School of Dentistry, University of Cuiabá, Cuiabá, MT, Brazil \\ 2)Department of Oral Sciences, School of Dentistry, Federal University of Goiás, Goiânia, GO, Brazil \\ 3)Department of Operative Dentistry and Dental Materials, Dental School, \\ Federal University of Uberlândia, Uberlândia, MG, Brazil
}

(Received January 10, 2014; Accepted February 27, 2014)

\begin{abstract}
The purpose of this study was to investigate the influence of gutta-percha solvents on the bond strength of fiberglass post to root canal dentin. Forty bovine incisors were decoronated, prepared, filled, and randomly distributed into four groups $(n=10)$ according to the gutta-percha solvent used: control, xylene, eucalyptol and orange oil. After root canal treatment, the posts were cemented into the prepared root canals using a resin-based cement. A micro pushout test was executed, and the patterns of failure were assessed with microscopy. The data were analyzed using two-way ANOVA followed by Tukey's test. The control group exhibited greater bond strength compared to the eucalyptol group in the cervical and middle thirds of the root $(P<0.05)$; however, it did not differ significantly from the xylene and orange oil groups $(P>0.05)$. No difference was observed in the values of the xylene, orange oil, and eucalyptol groups $(P>0.05)$. The cervical third had higher values than the apical third for all tested solvents $(P<0.05)$. Adhesive failure between resin cement and dentin was the most frequent type of failure. The use of xylene and orange oil as gutta-percha solvents did not influence the bond strength of fiberglass posts to root canal dentin. (J Oral Sci 56, 105-112, 2014)
\end{abstract}

Correspondence to Dr. Carlos Estrela, Department of Oral Sciences, Federal University of Goiás, Praça Universitária s/n, Sector Universitário CEP: 74605-220, Goiânia, GO, Brazil

E-mail: estrela3@terra.com.br

doi.org/10.2334/josnusd.56.105

DN/JST.JSTAGE/josnusd/56.105
Keywords: bond strength; fiber post; gutta-percha solvent; eucalyptol; endodontic retreatment.

\section{Introduction}

Endodontically treated teeth with significant loss of crown structure due to extensive caries, previous restorations, and/or fractures generally require a radicular post for the reestablishment of tooth esthetics and function $(1,2)$. Various procedures and products have been developed and proposed for the rehabilitation of teeth which underwent endodontic treatment (3). A fiberglass post is commonly used because of its favorable biomechanical properties compared to cast posts (1). Because of their similarities to dentin with respect to elastic properties, fiberglass posts permit a relatively regular stress distribution of the functional load to the root canal and its surrounding tissues, resulting in fewer catastrophic failures, including root fractures (3-5). In addition, fiberglass posts provide more esthetic outcomes for anterior teeth, allow a simpler post-endodontic restoration procedure (the laboratory step is eliminated because they can be prepared and molded in a single session), and are relatively easy to remove when endodontic retreatment is needed $(1,3)$.

The signs of endodontic treatment failure, including the presence of apical periodontitis and post-treatment symptoms, are important indicators that further intervention is required (6). Nonsurgical root canal retreatment is commonly indicated when the initial treatment has failed (7). Efficient removal of the root filling materials is required for retreatment, and many devices and tech- 
niques are employed to remove such materials. These include hand or rotary NiTi instruments, thermal and ultrasonic instruments and solvents $(8,9)$. A solvent is used to soften the master cone and improve the apical adaptation of the root canal, to make a gutta-percha paste that can be used for obturation, or to simplify the removal of filling materials from root canal system during retreatment $(9,10)$. The most commonly used gutta-percha solvent in endodontics is chloroform because it can solubilize gutta-percha more quickly than other solvents and is inexpensive and easily available (11-13). Nevertheless, the use of chloroform is prohibited by the U. S. Food and Drug Administration because of its potential carcinogenicity (14). Alternatives to chloroform have been suggested, including xylene (xylol), eucalyptol, halothane, terebinthina oil, and orange oil $(6,11-13,15$ 17).

During root canal retreatment, the radicular and coronal dentin is exposed to gutta-percha solvents. These solvents may modify the chemical constitution of the dentin surface and affect its interaction with the restorative and root filling materials (18). The effects of several chemical agents used during endodontic therapy on the bond strength of fiberglass posts to root canal dentin have been studied (2,19-23). However, studies addressing the fiberglass post bond strength to root canal dentin after root canal retreatment procedures are lacking. This study therefore analyzed the effects of three different guttapercha solvents on the bond strength of fiberglass posts cemented with a resin-based cement. The null hypothesis tested was that the solvent used has no effect on the bond strength of the fiberglass post to the root canal dentin, regardless of the part of the root canal.

\section{Materials and Methods}

Forty recently extracted bovine incisors with roots that were anatomically similar in size and shape and canals that were less than $1 \mathrm{~mm}$ in diameter with completely developed root apices were selected for the present study and stored in distilled water. This study was approved by the local Research Ethics Committee of Federal University of Goiás (Process \#256/2010). Before root canal preparation (RCP), each tooth was decoronated with a double-faced diamond disc (KG Sorensen, São Paulo, SP, Brazil) operated perpendicularly to its longitudinal axis to produce standardized roots of $15 \mathrm{~mm}$ length. The working length (WL) was established by subtracting 1 $\mathrm{mm}$ from the root length.

The root specimens were instrumented using the crown-down technique with BioRace rotary nickel-titanium instruments (FKG Dentaire, La Chaux-de-Fonds,
Switzerland). Apical enlargement was performed at a size of 40/0.04. After each instrument change during the RCP, the root canals were irrigated with $3 \mathrm{~mL}$ of $2.5 \%$ sodium hypochlorite (Pharm, Fitofarma, Goiânia, GO, Brazil). After completion of RCP, the canals were irrigated with 3 $\mathrm{mL}$ of $17 \%$ EDTA (Biodinâmica, Ibiporã, PR, Brazil) for 3 min to effectively remove the smear layer, then rinsed with $3 \mathrm{~mL}$ of sterile saline. The root canals were dried with sterilized paper points and filled with gutta-percha (Dentsply Maillefer, Ballaigues, Switzerland) and a calcium hydroxide-based sealer (Sealapex, SybronEndo, São Paulo, SP, Brazil) that were mixed according to the manufacturers' directions, using a cold lateral compaction technique. The excess of gutta-percha and endodontic sealer were removed with a heated instrument, the root canal openings were filled with glass-ionomer cement (Vidrion R, SS White, Rio de Janeiro, RJ, Brazil), and all samples were stored at $100 \%$ humidity for 8 weeks at $37^{\circ} \mathrm{C}$

The root specimens were then randomly divided into four experimental groups ( $n=10$ roots per group) according to the gutta-percha solvent material used. Group 1 did not receive root canal retreatment and was used as the control group. Group 2 had the coronal 3 $\mathrm{mm}$ of filling material removed with \#2-3 Gates Glidden drills (Dentsply Maillefer). The filling material was then gradually removed with \#10 and \#15 K-type files and xylene (Synth, Labsynth, Diadema, SP, Brazil) until the WL was reached, at which point the following BioRace files were used to remove the remainder of the filling material: $25 / 0.08,15 / 0.05,25 / 0.04,25 / 0.06$, $35 / 0.04,40 / 0.04,50 / 0.04$, and 60/0.02. Groups 3 and 4 were given the same retreatment procedures as Group 2, except that instead of xylene, eucalyptol (Maquira, Maringa, PR, Brazil) was used in Group 3, and orange oil (Biodinâmica) was used in Group 4. A total of $1 \mathrm{~mL}$ of endodontic solvent was used for each root specimen. During the retreatment procedure, the root canals were irrigated with $3 \mathrm{~mL}$ of $2.5 \%$ sodium hypochlorite. After root canal retreatment, the root canals were irrigated with $3 \mathrm{~mL}$ of $17 \%$ EDTA for $3 \mathrm{~min}$, rinsed with $3 \mathrm{~mL}$ of sterile saline, dried with sterilized paper points and reobturated as previously described. The root canal opening was then filled with glass-ionomer cement (Vidrion R, SS White, Rio de Janeiro, RJ, Brazil), and the roots were stored at $37^{\circ} \mathrm{C}$ and $100 \%$ humidity for 4 weeks. A single calibrated operator performed all the procedures.

After this storage period, a post space was prepared using \#1-4 Largo drills (Dentsply Maillefer) (WL $10 \mathrm{~mm}$ ), which corresponded to the 1.3 parallel-sided, serrated fiberglass posts (Reforpost \#2; Angelus, Londrina, PR, 
Table 1 Mean bond strength values in MPa (standard deviation) and statistical categories according to the Tukey test $(n=10)$

\begin{tabular}{lcccc}
\hline \multirow{2}{*}{ Root third } & & \multicolumn{2}{c}{ Gutta-percha solvents } & \\
& Control group & Xylene & Orange oil & Eucalyptol \\
\hline Cervical & $6.8 \pm 3.0^{\mathrm{Aa}}$ & $5.3 \pm 4.2^{\mathrm{ABa}}$ & $4.6 \pm 2.8^{\mathrm{ABa}}$ & $3.9 \pm 3.0^{\mathrm{Ba}}$ \\
Middle & $4.5 \pm 4.2^{\mathrm{Aab}}$ & $4.2 \pm 2.9^{\mathrm{Ba}}$ & $2.4 \pm 2.7^{\mathrm{ABb}}$ & $0.038^{*}$ \\
Apical & $2.4 \pm 1.4^{\mathrm{Ab}}$ & $1.6 \pm 1.8^{\mathrm{Ab}}$ & $1.3 \pm 1.6^{\mathrm{Ab}}$ & $0.03^{*}$ \\
$P$ & $0.008^{*}$ & $0.000^{*}$ & $0.000^{*}$ & $0.223^{\mathrm{Bb}}$ \\
\hline
\end{tabular}

$P: *$ Kruskal-Wallis

Capital letters compare groups in horizontal lines and lower-case letters in vertical lines.

Tukey test categories with same letter are not statistically different from each other $(P<0.05)$.

Brazil). The root canals were irrigated with $2.5 \%$ sodium hypochlorite after each bur change. After the post-space preparation, each root canal was rinsed with $17 \%$ EDTA and saline solution and dried with absorbent paper points. The fiberglass posts were cleaned with $70 \%$ alcohol, and a silane agent (Silano, Angelus) was applied with a microbrush for $1 \mathrm{~min}$. The self-adhesive resin cement (RelyX U100; 3M-ESPE, St. Paul, MN, USA) was prepared following to the manufacturer's directions, added to the root canal with the aid of an endodontic instrument and applied on the post. The post was seated to its full depth with digital pressure. Any excess cement was removed after $1 \mathrm{~min}$. Three min later, the self-adhesive resin cement was light-cured using a $1,200 \mathrm{~mW} \mathrm{~cm}^{-2}$ (RadiiCal; SDI, Bayswater, Australia) source for $40 \mathrm{~s}$ each on the cervical face of the specimen, along the long axis of the specimen, and oblique to the buccal and lingual surfaces, for a total of $120 \mathrm{~s}$. The specimens were then stored at $100 \%$ humidity and $37^{\circ} \mathrm{C}$ for $24 \mathrm{~h}$. Twenty-four $\mathrm{h}$ later, each specimen was sectioned perpendicularly to its long axis with the aid of a double-faced diamond disc (4" diameter $\times 0.012$ " thickness $\times 1 / 2$ "; Arbor, Extec, Enfield, CT, USA) and a precision saw (Isomet 1000, Buehler, Lake Bluff, IL, USA) at low speed with water cooling. This process was used to obtain two slices 1-mm in thickness from each third (the cervical, middle, and apical thirds) of the root, for a total of six slices per root. The root specimens were then submitted to a micro pushout test in a universal testing machine (Instron 5960 Dual Column Tabletop Testing Systems, Instron, Barueri, SP, Brazil). A compressive load was applied at $0.5 \mathrm{~mm} \mathrm{~min}^{-1}$ in the apical-coronal direction until failure occurred. The bond strength in MPa was calculated by dividing the load at failure $(\mathrm{N})$ by the area of the bonded interface. The area of the bonded interface was calculated as follows: $\mathrm{A}=2 \pi \mathrm{r} \times \mathrm{h}$, where $\mathrm{A}$ is the area of the bonded interface, $\pi=3.14, \mathrm{r}$ is the radius of the post segment $(\mathrm{mm})$, and $\mathrm{h}$ is the thickness of the post segment (mm) (23-25).
The failure pattern was determined after all specimens were air-dried. Both sides of the slices were analyzed using a light microscope at $\times 40$ magnification (Carl Zeiss, Jena, Germany). The failure pattern was categorized into six types: (i) adhesive between the post and resin cement; (ii) adhesive between resin cement and root dentin; (iii) cohesive in cement; (iv) cohesive in dentin; (v) cohesive in post; and (vi) mixed, between post, resin cement and root dentin.

The Statistical Package for Social Sciences (IBM SPSS 21, IBM Co., New York, NY, USA) was used for statistical analysis. The Kolmogorov-Smirnov test was used to test normality. The influences of the solvents on bond strength were analyzed using the two-way analysis of variance (ANOVA) in a split-plot arrangement, with the main plot for the gutta-percha solvent and the subplots for the root canal thirds. The Tukey test was used for multiple comparisons $(\alpha=0.05)$. The percentage of each type of failure within each group was calculated.

\section{Results}

Table 1 shows the mean bond strength values, the standard deviations and the differences within the groups after the micropush-out test. There were statistically significant differences among the groups $(P<0.05)$. The control group exhibited significantly higher bond strength compared with the eucalyptol group in the cervical and middle thirds $(P<0.05)$; however, the control group did not differ significantly from the xylene and orange oil groups $(P>0.05)$. No significant difference was observed between the values for the xylene, orange oil, and eucalyptol groups $(P>0.05)$. The cervical third had higher values than the apical third, regardless of the gutta-percha solvent tested $(P<0.05)$. Table 2 shows the failure pattern. Interestingly, cement-dentin adhesive failure was the most prevalent type of failure in all groups. No adhesive failure was observed between the fiberglass post and resin-cement (Fig. 1). 
Table 2 Failure modes for experimental groups (\%)

\begin{tabular}{lcccccc}
\hline \multirow{2}{*}{ Gutta-percha solvents } & \multicolumn{7}{c}{ Failures modes } \\
& i & ii & iii & iv & v & vi \\
\hline Control group & - & 80.0 & 1.7 & - & 1.7 & 16.6 \\
Xylene & - & 83.4 & 5.0 & 1.6 & 1.7 & 8.3 \\
Orange oil & - & 81.7 & 3.3 & - & - & 15.0 \\
Eucalyptol & - & 91.7 & 3.3 & - & 1.7 & 3.3 \\
\hline
\end{tabular}

(i) Adhesive: post and cement; (ii) Adhesive: cement and dentin; (iii) Cohesive: cement; (iv) Cohesive: dentin; (v) Cohesive: post; (vi) Mixed: post, cement and dentin
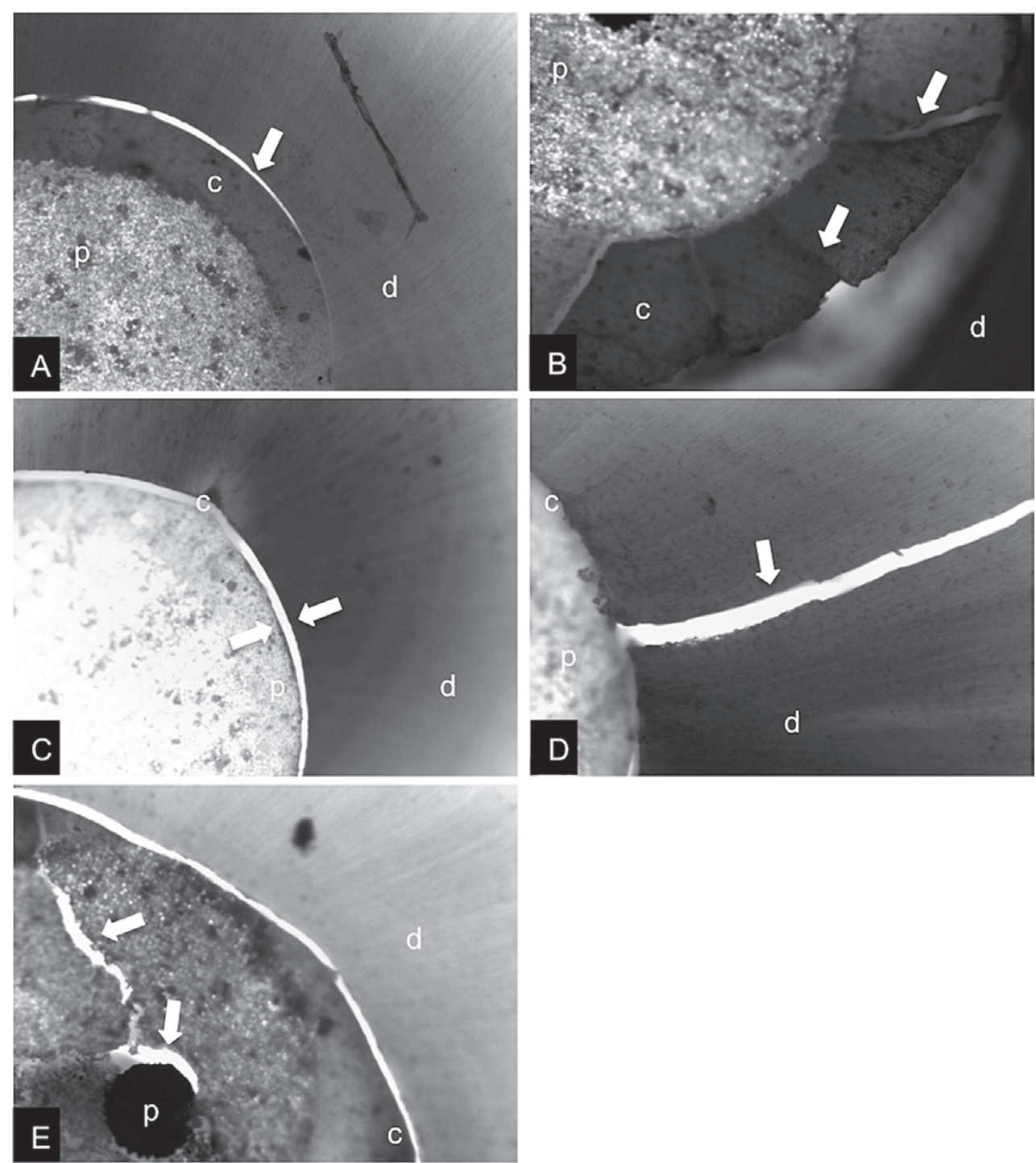

Fig. 1 Light microscopy of failure mode: (A) adhesive between resin cement and root dentine; (B) cohesive in cement; (C) mixed, among post, resin cement and root dentine; (D) cohesive in dentine; (E) cohesive in post. Arrows point to failure region. d, dentine; c, cement; p, post

\section{Discussion}

The use of eucalyptol affected the bond strength between the fiberglass post and the root canal dentin in the cervical and middle thirds. In addition, the bond to the root dentin varied according to the third of the root canal being assessed. Thus, the results led to partial rejection of the null hypothesis.

The methodology used in the present study has been broadly used in the analysis of adhesive bond strength. Bond strength experiments are often conducted to screen 
new materials and explore experimental variables (26). Microtensile and push-out methods have been confronted, and the results seem to indicate that fewer specimens are lost in the push-out tests, making them more efficient and reliable than the microtensile tests (24). Additionally, the push-out tests distribute stress more regularly and generate less variability in the mechanical test results. Thus, this methodology is recommended to study the bond strength between fiberglass posts and root canal dentin (25). Chen et al. (27) evaluated the effects of pin diameter, specimen thickness and elastic modulus of the filling material on bond strength measurements and found that all of these variables influenced the push-out bond strength. This means that bond strength values obtained from studies with different experimental setups cannot be compared. A better understanding of how each variable affects the bond strength will be required for the establishment of a rigorous set of guidelines for the push-out test.

The present study made use of bovine teeth, as human teeth are difficult to collect for research purposes $(20,23)$. Bovine teeth are easier to collect, their tooth age can be standardized and the risk of transmitting infectious diseases is minimal $(20,28)$. In addition, previous studies have shown that bovine and human teeth present similar properties $(28,29)$.

A large variety of products are commercially available for cementation of fiberglass posts (24). In the current study, self-adhesive resin cement was used as the luting material. This resin cement combines an adhesive agent and cement in one application, thus eliminating the need for pretreatment and producing a stronger dentin bond than conventional resin cements (23). The resin-based cement works through different mechanisms: (A) the acidic monomers hybridize to the dentin and (B) the resin chemically interacts with the hydroxyapatite. Gerth et al. (30) observed a strong chemical reaction between RelyX Unicem and calcium from hydroxyapatite. This reaction most likely results from chelation of the calcium ions by the acid group that generates chemical adherence to hydroxyapatite in the tooth structures. Chemical interactions between hydroxyapatite and the resin-based cement are effective within the root canal, and such interactions may be more important for root dentin bonding than the ability of the same product to hybridize dentin (31).

The negative effects on bond strength of several chemical agents used during root canal treatment, including endodontic irrigants (sodium hypochlorite, EDTA, and hydrogen peroxide), calcium hydroxide and eugenol of medicaments and sealers, have been well-documented $(2,19-23)$. However, few studies have assessed the influ- ence of gutta-percha solvents on the bonding process itself $(10,32)$. Erdemir et al. (10) assessed the influence of two gutta-percha solvents (chloroform and halothane) on the microtensile bond strength to root canal dentin and observed that gutta-percha solvents have an adverse effect on the bond strength between adhesive cements and root canal dentin. Shokouhinejad et al. (32) demonstrated that retreatment procedures might affect the adhesion of refilling materials to the dentinal walls, thus jeopardizing their bond strength to radicular dentin following endodontic retreatment. In this study, the chloroform used in retreatment had an adverse effect on the bond strength of Resilon/Epiphany SE after root canal reobturation.

It has been reported that gutta-percha solvents can alter the chemical structure and composition of human dentin $(7,18,33)$. Rotstein et al. (7) assessed the effects of chloroform, xylene, and halothane on the microhardness of human enamel and dentin. Their results indicated that treatment with gutta-percha solvents significantly reduced the microhardness of both enamel and dentin. This effect was time-dependent as well as significant after 5 min of treatment in most cases. Gutta-percha solvents may affect the organic elements of enamel and dentin, promoting enlargement of the intercrystalline spaces and thus increasing the porosity and permeability of dental tissues. Erdemir et al. (33) studied the effect of chloroform and halothane on the calcium, phosphorus, magnesium, potassium, and sulfur content of root dentin. They observed a significant decrease in the calcium levels after the use of halothane, and a significant decrease in the magnesium levels after the use of all solvent types. Kaufman et al. (18) demonstrated that the calcium and phosphorus levels of human dentin were altered after treatment with gutta-percha solvents (chloroform, xylene, and Endosolv-E) but that these changes were minimal and statistically insignificant. In contrast, Doğan et al. (17) showed that neither warming nor prolonged treatment time with gutta-percha solvents (including xylene, halothane, eucalyptol, orange oil, and chloroform) had a significant effect on the histochemical composition of a cut human dentin surface. Any changes to the organic and inorganic components of dentin may affect its adhesion to dental materials (7).

In the present study, three different gutta-percha solvents were examined to investigate the adhesion capability of fiberglass post after retreatment procedures. The results clearly indicate that the use of eucalyptol significantly influences the bond strength between fiberglass posts and root canal dentin. The eucalyptol group exhibited the lowest bond strength values (Table 
1); however, no significant difference was found between the eucalyptol group and the xylene and orange oil groups $(P>0.05)$. It is likely that the low cervical and middle third bond strength values registered for the eucalyptol group are associated to its limited ability to solubilize gutta-percha and thereby clean the root canal wall $(11,12,15,34)$. The softened root filling material can easily be compacted into the dentinal tubules, where it cannot be removed (9), and may thus reduce the bond strength of resin-based cements. Complete removal of filling materials from dentinal tubules seems essential to improve the adaptation of sealers and the adhesion of the cements used for posts (9).

The analysis by root canal third showed that the bond strength value was generally higher in the cervical thirds and lower in apical areas, as reported in previous investigations $(20,35,36)$. The decreased bond strength in the apical third could be due to the presence of large amount of gutta-percha and sealer in the root canal walls after the new endodontic procedure (34). In general, root canal cleanliness in the apical third is worse than in the coronal and middle thirds (34). The presence of large amount of filling material in the apical third and the absence of a homogeneous bond interface (20) could therefore reduce the contact area between dentin and cementing agent, thus reducing polymerization of the resin cement. Limitations in the flow of the viscous cement, difficulty accessing the apical area, the factor cavity configuration (C-factor) (24) and differences in the dentin architecture in different areas of the root canal $(35,37)$ may have also contributed to these results.

The employment of failure pattern for all specimens tested is an obligation to clarify the performance of study factor during push-out test. In the present study, the analysis of the root slices demonstrated the predominance of adhesive failure between the resin cement and root dentin in all groups. This means that the dentin surface appeared clean and devoid of resin cement. This result may be related to filling material residue left on the root canal walls and inside dentinal tubules and on the low capacity of the self-adhesive resin cement for dentin hybridization (9). In addition, the gutta-percha solvents used may have changed the chemical and structural composition of the root canal dentin, thereby altering the observed bond strength $(7,10)$. These results are in conformity with the results of a previous study demonstrating that fiberglass posts cemented with self-adhesive resin are weakest at the resin cement-root dentin interface (22). However, the failure types described by Bitter et al. (31) contrast with the results obtained in the present study, as mainly adhesive failures were described between the post and cement.

A primary aim of endodontic retreatment is to obtain access to the entire length of the root canal (7).Zakariasen et al. (8) advised that whenever possible, endodontic retreatment should be accomplished without the use of toxic solvents. When deciding which solvent to use for retreatment, the practicality of efficient use of time and safety must be balanced $(7,13)$. Xylene, eucalyptol, and orange oil are known solvents of gutta-percha that are available for clinical use. Xylene has a solubilizing effect on gutta-percha that is similar to that of chloroform (11), but it is very toxic (12). Eucalyptol has been reported to be safe and efficient; however, at room temperature, eucalyptol does not solubilize gutta-percha as rapidly as chloroform and xylol $(11,12,15)$. Eucalyptol must be heated to be clinically effective as a solvent (12). Orange oil was initially proposed for use as a solvent of zinc oxide and a eugenol sealer (38). A previous study (16) showed that orange oils soften the gutta-percha cones similarly to xylol but without its deleterious effects, making it an attractive alternative solvent.

Although the samples in this study were not submitted to thermal and mechanical cycling to precisely simulate intra-oral environment, the results are still useful to clinicians. Future long-term clinical studies will be needed to evaluate the bonding behavior of adhesively cemented fiberglass posts in teeth subjected to retreatment procedures. In conclusion, the results demonstrate that the use of xylene and orange oil as gutta-percha solvents during root canal retreatment produces no significant differences in the bond strength of the fiberglass posts cemented to radicular dentin. The use of eucalyptol significantly decreased the bond strength of fiberglass posts in the cervical and middle thirds of the roots, and the cervical third showed higher bond strength values than the apical third.

\section{Acknowledgments}

This study was supported in part by grants from the National Council for Scientific and Technological Development (CNPq) grant \#306394/2011-1 to CE.

\section{References}

1. Schwartz RS, Robbins JW (2004) Post placement and restoration of endodontically treated teeth: a literature review. J Endod 30, 289-301.

2. Cecchin D, Almeida JFA, Gomes BPFA, Zaia AA, Ferraz CCR (2012) Deproteinization technique stabilizes the adhesion of the fiberglass post relined with resin composite to root canal. J Biomed Mater Res B Appl Biomater 100B, 577-583.

3. Soares CJ, Valdivia AD, da Silva GR, Santana FR, Menezes 
MS (2012) Longitudinal clinical evaluation of post systems: a literature review. Braz Dent J 23, 135-140.

4. Akkayan B, Gülmez T (2002) Resistance to fracture of endodontically treated teeth restored with different post systems. J Prosthet Dent 87, 431-437.

5. Barjau-Escribano A, Sancho-Bru JL, Forner-Navarro L, Rodríguez-Cervantes PJ, Pérez-Gónzález A, Sánchez-Marín FT (2006) Influence of prefabricated post material on restored teeth: fracture strength and stress distribution. Oper Dent 31 , 47-54.

6. Estrela C, Guedes OA, Pereira-Júnior W, Esponda L, Cruz AG (2009) Diagnosis of endodontic failure. In: Endodontic science, Estrela C ed, Artes Médicas, São Paulo, 883-915.

7. Rotstein I, Cohenca N, Teperovich E, Moshonov J, Mor C, Roman I et al. (1999) Effect of chloroform, xylene, and halothane on enamel and dentin microhardness of human teeth. Oral Surg Oral Med Oral Pathol Oral Radiol Endod 87, 366-368.

8. Zakariasen KL, Brayton SM, Collinson DM (1990) Efficient and effective root canal retreatment without chloroform. $\mathrm{J}$ Can Dent Assoc 56, 509-512.

9. Horvath SD, Altenburger MJ, Naumann M, Wolkewitz M, Schirrmeister JF (2009) Cleanliness of dentinal tubules following gutta-percha removal with and without solvents: a scanning electron microscopic study. Int Endod J 42, 10321038 .

10. Erdemir A, Eldeniz AU, Belli S, Pashley DH (2004) Effect of solvents on bonding to root canal dentin. J Endod 30, 589-592.

11. Wennberg A, Ørstavik D (1989) Evaluation of alternatives to chloroform in endodontic practice. Endod Dent Traumatol 5, 234-237.

12. Wourms DJ, Campbell AD, Hicks ML, Pelleu GB Jr (1990) Alternative solvents to chloroform for gutta-percha removal. J Endod 16, 224-226.

13. Wilcox LR (1995) Endodontic retreatment with halothane versus chloroform solvent. J Endod 21, 305-307.

14. United States Food and Drug Administration (1976) Chloroform use as an ingredient (active or inactive) in drug products. Federal Reg. No. 26845, US Government Printing Office, Washington DC, 47-48.

15. Kaplowitz GJ (1990) Evaluation of gutta-percha solvents. J Endod 16, 539-540.

16. Pécora JD, Spanó JCE, Barbin EL (1993) In vitro study on the softening of gutta-percha cones in endodontic retreatment. Braz Dent J 4, 43-47.

17. Doğan H, Taşman F, Çehreli ZC (2001) Effect of gutta-percha solvents at different temperatures on the calcium, phosphorus and magnesium levels of human root dentin. J Oral Rehabil 28,792-796.

18. Kaufman D, Mor C, Stabholz A, Rotstein I (1997) Effect of gutta-percha solvents on calcium and phosphorous levels of cut human dentin. J Endod 23, 614-615.

19. Teixeira CS, Pasternak-Junior B, Borges AH, Paulino SM, Sousa-Neto MD (2008) Influence of endodontic sealers on the bond strength of carbon fiber posts. J Biomed Mater Res B Appl Biomater 84, 430-435.

20. Menezes MS, Queiroz EC, Campos RE, Martins LRM, Soares CJ (2008) Influence of endodontic sealer cement on fiberglass post bond strength to root dentine. Int Endod J 41, 476-484.

21. Demiryürek EÖ, Külünk Ş, Yüksel G, Saraç D, Bulucu B (2010) Effects of three canal sealers on bond strength of a fiber post. J Endod 36, 497-501.

22. Dimitrouli M, Günay H, Geurtsen W, Lührs AK (2011) Pushout strength of fiber posts depending on the type of root canal filling and resin cement. Clin Oral Investig 15, 273-281.

23. Soares CJ, Pereira JC, Valdivia ADCM, Novais VR, Meneses MS (2012) Influence of resin cement and post configuration on bond strength to root dentine. Int Endod J 45, 136-145.

24. Goracci C, Tavares AU, Fabianelli A, Monticelli F, Raffaelli O, Cardoso PC et al. (2004) The adhesion between fiber posts and root canal walls: comparison between microtensile and push-out bond strength measurements. Eur J Oral Sci 112, 353-361.

25. Soares CJ, Santana FR, Castro CG, Santos-Filho PCF, Soares PV, Qian F et al. (2008) Finite element analysis and bond strength of a glass post to intraradicular dentin: comparison between microtensile and push-out tests. Dent Mater 24, 1405-1411.

26. Armstrong S, Geraldeli S, Maia R, Raposo LHA, Soares CJ, Yamagawa J (2010) Adhesion to tooth structure: a critical review of "micro" bond strength test methods. Dent Mater 26, e50-62.

27. Chen WP, Chen YY, Huang SH, Lin CP (2013) Limitations of push-out test in bond strength measurement. J Endod 39, 283-287.

28. Soares CJ, Barbosa LM, Santana FR, Soares PBF, Mota AS, Silva GR (2010) Fracture strength of composite fixed partial denture using bovine teeth as a substitute for human teeth with or without fiber-reinforcement. Braz Dent J 21, 235-240.

29. Nakamichi I, Iwaku M, Fusayama T (1983) Bovine teeth as possible substitutes in the adhesion test. J Dent Res 62, 10761081.

30. Gerth HU, Dammaschke T, Züchner H, Schäfer E (2006) Chemical analysis and bonding reaction of RelyX Unicem and Bifix composites--a comparative study. Dent Mater 22, 934-941.

31. Bitter K, Paris S, Pfuertner C, Neumann K, Kielbassa AM (2009) Morphological and bond strength evaluation of different resin cements to root dentin. Eur J Oral Sci 117, 326-333.

32. Shokouhinejad N, Sabeti MA, Hasheminasab M, Shafiei F, Shamshiri AR (2010) Push-out bond strength of Resilon/ Epiphany self-etch to intraradicular dentin after retreatment: a preliminary study. J Endod 36, 493-496.

33. Erdemir A, Eldeniz AÜ, Belli S (2004) Effect of gutta-percha solvents on mineral contents of human root dentin using ICP-AES technique. J Endod 30, 54-56.

34. Hülsmann M, Bluhm V (2004) Efficacy, cleaning ability 
and safety of different rotary NiTi instruments in root canal retreatment. Int Endod J 37, 468-476.

35. Zorba YO, Erdemir A, Turkyilmaz A, Eldeniz AÜ (2010) Effects of different curing units and luting agents on push-out bond strength of translucent posts. J Endod 36, 1521-1525.

36. Topcu FT, Erdemir U, Sahinkesen G, Mumcu E, Yildiz E, Uslan I (2010) Push-out bond strengths of two fiber post types bonded with different dentin bonding agents. J Biomed
Mater Res B Appli Biomater 93, 359-366.

37. Ribeiro RG, Marchesan MA, Silva RG, Sousa-Neto MD, Pécora JD (2010) Dentin permeability of the apical third in different groups of teeth. Braz Dent J 21, 216-219.

38. Martos J, Bassotto AP, González-Rodríguez MP, FerrerLuque CM (2011) Dissolving efficacy of eucalyptus and orange oil, xylol and chloroform solvents on different root canal sealers. Int Endod J 44, 1024-1028. 